\title{
Illicit Substance
}

National Cancer Institute

\section{Source}

National Cancer Institute. Illicit Substance. NCI Thesaurus. Code C79097.

Something (as drugs or alcoholic beverages) deemed harmful and usually subject to legal restriction. 